\title{
Method Development and Validation for Spectrophotometric Determination of Ascorbic Acid in M. stenopetala Leaves Through Catalytic Titration with Hexavalent Chromium
}

\author{
Habtamu Aberra \\ Chemistry department, Dilla College of Teacher Education, PO box 345, \\ Dilla College of Teacher Education, Dilla \\ Mitiku Abdisa* \\ Chemistry department, Dilla University, P.o.box. 419, Dilla University, Dilla \\ Alemayehu P. Washe (PhD) \\ Chemistry department, Hawasa University, PO box 05, Hawasa University, Hawasa
}

\begin{abstract}
M. stenopetala has gained attention recently in Ethiopia due to its multiple uses. It is a drought tolerant fast growing indigenous tree mainly planted and maintained for its nutritional value. An ascorbic acid excess can lead to gastric irritation and the metabolic product of vitamin C (oxalic acid) can cause renal problems. Thus, its level in food stuffs should be monitored. Hence, in this project, it was aimed to develop a novel spectrophotometer method for determination of ascorbic acid content in M. Stenopetala through Catalytic titration with Hexavalent chromium. The developed method was validated against HPLC as standard technique. Cr (VI) was used as UV-active material and $\mathrm{Mn}$ (II) used as catalyst. Determination of AA was based on the decrease in absorbance of the $\mathrm{Cr}$ (VI) solution as a result of its reaction with AA. Factors influencing the reduction of $\mathrm{Cr}$ (VI), including incubation time, solution $\mathrm{pH}$ and background concentration ratio had been optimized. The theoretical detection limit and Limit of quantification were calculated to be 0.00154 and $0.005134 \mathrm{mg} / \mathrm{ml}$, respectively. Out of the 3 different area of Ms Leave sample studied, FMs from Arbaminch contained highest concentration $(237 \pm 0.001 \mathrm{mg} / 100 \mathrm{~g}) \mathrm{of} \mathrm{AA}$, Followed by FMs from Konso $(233 \pm 0.48 \mathrm{mg} / 100 \mathrm{~g}$ and FMs from Dilla $(21 \pm 0.48 \mathrm{mg} / 100 \mathrm{~g})$, respectively. But it was reduced significantly after boiling for ten minute. The level of AA content in the analyzed Ms Leave samples was found to decrease with increasing cooking time. Cooked Ms Leave sample contained lower concentration of AA than Fresh M. stenopetala leave sample. All studied Ms Leave samples contained relatively acceptable range or moderate amounts of total AA $(200-250 \mathrm{mg} / 100 \mathrm{~g})$ and the results obtained from the modified UV-vis Spectrophotometric and HPLC methods were statistically consistent.

Keywords: Ascorbic acid determination, Catalytic Titration, Hexavalent Chromium, HPLC, M. stenopetala Leave, UV-Vis spectrometric

DOI: $10.7176 /$ FSQM/94-01
\end{abstract}

Publication date: February $29^{\text {th }} 2020$

\subsection{Background of the Study}

Moringa is the sole genus of the flowering plant family Moringaceae, order Brassicales. It comprises 14 species of trees and shrubs namely in tropical and sub tropical climate. The genus moringa consists of 14 species to which M.stenopetala belongs (family Moringaceae) [1]. $M$. stenopetala is often named as African Moringa tree because it is native to southern Ethiopia, North Kenya and Eastern Somalia. It's widely consumed other part of the world due to high nutritional value and antioxidant effect. It is not as widely known as its close relative $M$. oleifera which is native to India, Africa, Arabia, Southeast Asia, and South America.

In Ethiopia it is only recently that the health benefits and nutritional value when consuming of M.stenopetala leave was recognized. It is grown in different parts of the country; however, it is consumed only in certain areas of the countries. M. stenopetala is widely grown and consumed as a frequently in konso. Other areas where it is consumed include Arbaminch, Bale, Wollayta, Sedama and other southern part of Ethiopia [2, 3]. Due to the scientific developments on M. stenopetala, it is becoming very popular in the country and its consumption is also extending to other part of Ethiopia regions. This is due to almost all parts of the plant are used culturally for its nutritional value and the applauded health benefits that includes prevention of hypertension, reduce blood pressure, anti-malarial and anti-cancer effects[4,5].The leaves of M. senopetala can be eaten fresh and cooked[5]. The leaves contain all essential amino acid and are reaching in protein and mineral [6, 7]. M. senopetala seed contain active coagulant compound in the seed for water treatment $[8,9]$.

M. stenopetala has attracted huge scientific interest due to its aforementioned benefits. Describe the scientific works. Even though various studies have been focused on nutritional values and phytochemicals activities, more specifically antioxidants effect [10]. There are also other research interests to use M. stenopetala as adsorbent 
material for water purification [9]. In southern regional state of Ethiopia the M. stenopetala has commonly used as source of food. Nevertheless, as far as our knowledge is concerned, there is very limited information regarding the level of dietary acids in M.stenopetala leaves.

The researcher in this study sought to Method Development and Validation for Spectrophotometric determination of Ascorbic Acid in M.stenopetala leave through Catalytic Titration with Hexavalent Chromium. M.stenopetala leaves were collected from the three selected area in southern regional state of Ethiopia namely: Konso, Arbaminch and Dilla and then analyzed by using spectrophotometer and chromatograph method.

Dietary acids are among the important constituents of vegetables whose level should be controlled in the food for consumption. Dietary acids include ascorbic acid, oxalic acid, malic acid, tartaric acid, citric acid. Among these acids AA is a weak acid which play important role in normal growth and health status of a person. AA has also known as vitamin $\mathrm{C}$, which used to prevent from the deficiency of diseases called scurvy. However, elevated concentration has been negative effects. These include gastric irritation and metabolic product of vitamins $\mathrm{C}$ (oxalic acid) can cause renal problem. The normal level should be monitored in foods for consumption. According to RDA limits dietary allowance of AA in food to be $90 \mathrm{mg}$ for male and $75 \mathrm{mg}$ for female. The Food and Agricultural Organization of the United Nations (FAO) then their vitamin C intake would be between 210-280 mg.

$\mathrm{OA}$ is another dietary acid whose level should be controlled in the foods for human consumption. Low oxalate concentration level $(<10 \mathrm{mg} / 100 \mathrm{~g})$, Moderate oxalate concentration level $(11-25 \mathrm{mg} / 100 \mathrm{~g})$ and high oxalate concentration level $(29-99 \mathrm{mg} / 100 \mathrm{~g})$. OA is important to increase the metabolic activities of human body but when excessive intake of food and drink containing oxalate leads to calcium oxalate stone (kidney stone). In addition, excessive intake of vitamin $\mathrm{C}$ which metabolized to oxalate may lead to hyper calcicuria and an increase in stone formation $[11,12,13]$. According to Sienera. $\mathrm{R}$ et al [2006]. Dietary oxalates are usually restricted to 50 milligrams per day and no other oxalate sources could be eaten during the day [14].

Hence in this project, it was aimed to develop method and validation for spectrophotometer determination of ascorbic acid content in M. Stenopetala through Catalytic titration with Hexavalent chromium.

Dietary acids such as ascorbic acid, malic acid, acetic acid, tartaric acid and oxalic acid are among the important constituents of vegetables that can determine their nutritional value. Ascorbic acid (vitamin $\mathrm{C}$ ) could be used in effective remediation of $\mathrm{Cr}(\mathrm{VI})$-contaminated soils and groundwater in a wide range of $\mathrm{pH}$, with or without sunlight [15]. It is also important for the absorption of iron in the gut, carnitine biosynthesis and as reducing agent in the cellular metabolism, AA has a capacity to relief disease called scurvy .Therefore, it is important to study whether the level of AA in the edible part of the plant is optimum to play such roles or above the optimum to cause undisclosed side effects such as gastric irritation and the metabolic product of vitamin $\mathrm{C}$ (oxalic acid) can cause renal problems. However, M. stenopetala has been many beneficial for human being; Most of these benefits are linked to its nutritional and antioxidant activities [21]. Since AA has also in some level of antioxidant properties. It is important to study weather AA is contributing to the claimed antioxidant activities of Moringa stenopetala leaves. In addition to that it is thus important to determine its level in M.stenopetala leaves to suggest on any cautions that might be taken by consumers and pharmacological industries. Thus, in the present study the amount of Ascorbic acid in green leafy vegetables (M. stenopetala) was determined by indirect UV -Vis spectrophotometer and HPLC method. To achieve the desired objectives, the study sought answers to the following research questions

1. Can a reaction of ascorbic acid with Hexavalent chromium (Cr (VI)) in presence of Mn (II) as a catalyst be used for Spectrophotometric determination of ascorbic acid?

2. Is there quantitative relationship between the effects of ascorbic acid on absorbance of $\mathrm{Cr}(\mathrm{VI})$ in presence of $\mathrm{Mn}$ (II)?

3. What are the factors that affect the reaction rate or extent of reaction of ascorbic acid with $\mathrm{Cr}$ (VI) in presence of Mn (II)?

4. Can a Spectrophotometric method based on catalytic titration of Ascorbic acid with Cr (VI) in presence of Mn (II) be applied for the determination of Ascorbic acid in selected M.stenopetala leave sample?

5. How is the level of Ascorbic acid in different varieties of M.stenopetala leave compared?

6. Does cooking of M.stenopetala leave decrease the level of Ascorbic acid?

\section{MATERIALS AND METHODS}

\subsection{Chemicals and reagents:}

Analytical grade reagent chemicals were employed for the preparation of all solutions. The chemical reagents used in this experiment include Methyl-red indicator, $0.5 \%$ (v/v) $\mathrm{H}_{3} \mathrm{PO}_{4}, \mathrm{CH}_{3} \mathrm{CN}, 0.5 \%(\mathrm{v} / \mathrm{v}) \mathrm{NaH}_{2} \mathrm{PO}_{4}, \mathrm{C}_{4} \mathrm{H}_{6} \mathrm{O}_{5}$, distilled water, tap water , $\mathrm{MnCl}_{2}$ and $\mathrm{K}_{2} \mathrm{Cr}_{2} \mathrm{O}_{7}$ as the source of divalent manganese and hexavalent chromium (analytical reagent, Germany) were used as catalyst and oxidant, respectively.during reduction of hexavalent chromium by ascorbic acid . Stock solution of $\left(\mathrm{C}_{2} \mathrm{O}_{4}(\geq 99,5 \%), \mathrm{C}_{6} \mathrm{H}_{8} \mathrm{O}_{6},(\geq 99,9 \%)\right.$ and $\mathrm{CH}_{3} \mathrm{OH}($ Yeshadam trading, Addis Ababa Ethiopia). 


\subsection{Instruments}

Single beam UV-Vis spectrophotometer (model CECIL 121, England) for recording absorbance measurement, Wavelength range 200-800 $\mathrm{nm}$, equipped with deuterium lamp was used for recording the absorbance measurement and HPLC with VWD/DAD. Digital $\mathrm{pH}$ meter for measuring the $\mathrm{pH}$ of the sample. Desiccators, rotator evaporator, Oven with air flow of $60^{\circ} \mathrm{C}-105^{\circ} \mathrm{C}$, slicer, Mechanical mill or chopper and Boiler.

\subsection{Sample Source and Study Area}

The sampling was local village around area of Konso, Arbaminch and Dilla and Sampling was conducted in June 2018. Konso, Arbaminch and Dilla city are located in southern nation and nationality regional state of Ethiopia, $1000 \mathrm{~km}, 750 \mathrm{~km}$ and $500 \mathrm{~km}$ south respectively, Which far away from the capital city of Ethiopia (Addis Ababa). In the central part of Ethiopia rift valley at an altitude of $1,680 \mathrm{~m}$ at altitude $8^{0} 04^{\prime} \mathrm{N}$ and altitude of $38018^{\prime} \mathrm{E}$ longitude.

\subsection{Sample preparation for M. Stenopetala leaves}

The sample (M. stenopetala leave) which collected from the field and it was washed with distil water and identify the edible parts of all the plants were selected. The inedible portions of sample were recorded and discarded. The M. stenopetala leaves samples were divided into two portions (Raw and cooked). The raw (fresh) sample was chopped into small pieces using Knife. All of the homogenized samples were dried in an oven for $24 \mathrm{hr}$ at 25 $75^{\circ} \mathrm{C}$. The temperature was studied over the range $25-75^{\circ} \mathrm{C}$. The $25^{\circ} \mathrm{C}$ was considering optimum because at higher temperature there were AA losses. The dried material was ground into a fine powder by using mortar and pestle. The powdered material was sealed in an aluminum foil plastic bag until analysis could commence. Macerate, 50gm of each M.stenopetala leave powder was weighted in to a $500 \mathrm{ml}$ shaking bottle and dissolve with $150 \mathrm{ml}$ of methanol for $48 \mathrm{hr}$ at $250 \mathrm{rpm}$ under shaker and allowed it was mixed. It was removed from the shaker and to stand until clear boundaries were observed between the organic and aqueous phases (residue). The organic phase was separated from aqueous phase by using the filter paper and collected in clean and dry flasks. The aqueous phase (in each case) was extracted three times with each $20 \mathrm{ml}$ of methanol. Few grams of anhydrous $\mathrm{NaH}_{2} \mathrm{SO}_{4}$ (drying agent) were added to the organic phases to remove traces of water molecules from the extracted crude AA. The organic solvent (methanol) that was used for the extraction was removed under reduced pressure (rotator evaporator) at $30-50{ }^{\circ} \mathrm{C}$ and crude AA extracts were weighted and kept in refrigerator until used for further analysis in case of the cooked portion of $\mathrm{M}$. stenopetala leaves sample was boiled in a temperature range of 25-60 ${ }^{\circ} \mathrm{C}$ for 10 minutes using hot plate with magnetic stirrer. The hot samples were cooled in cold water. The water discarded using filter paper. The cooked Ms Leaves were chopped into small pieces. Consistently, the same extracted procedure was followed for the sample preparation of cooked portion of M.stenopetala leaves.

\subsection{Physicochemical characterization.}

\subsubsection{Determination of $\mathbf{p H}$}

For determination of $\mathrm{pH}$ in selected M. Stenopetala leave the method of AOAC (2000) was adopted and digital pH meter ((Model HI9024, HANNA Instrument) was used. It is standardized using standard pH buffers. Sample solution was taken in the beaker and inserted. When the first reading was completed, the electrode was rinsed with distilled water and dried-up with tissue paper. Similarly, as a continue series, all other samples were determined accordingly [17].

\subsubsection{Moisture content analysis}

The moisture content analysis was carried out, the sample materials were taken in a flat-bottom dish (pre-weighed) as $\mathrm{W}_{1}$ and the weighed sample as $\mathrm{W}_{2}$ was immediately kept overnight in an oven and dried at $25-55^{\circ} \mathrm{C}$ for 24 hour until constant weight was obtained after which it was allowed to cool for 1 hour and reweighed. The final weight was noted as $\mathrm{W}_{3}$. The process was repeated for all the samples. The loss in weight was regarded as a measure of moisture content which was calculated for all the samples by using the following formula [18].

$$
\% \text { moisture }=\frac{\text { Loss in weight }(\mathrm{W} 2-\mathrm{W} 3)}{\text { Weight of sample before drying }(\mathrm{W} 2-\mathrm{W} 1)} \times 100
$$

Then, the moisture content of each of the sample was determined, and all the samples were ground to fine particles, using milling machine, and a sieved $(<2 \mathrm{~mm})$.

\subsection{Ascorbic acid determination by UV-Vis spectrophotometer}

\subsubsection{Extraction of ascorbic acid}

$1.00 \mathrm{~g}$ of each crude extract sample was weighed and dissolved $100 \mathrm{ml}$ of volumetric flask in distill water and diluting to mark. The mixture was then filtered through Whatman filter paper. The first $60 \mathrm{ml}$ filtrate was discarded and the rest was retained for analysis. Then $0.335 \mathrm{mM} \mathrm{K}_{2} \mathrm{Cr}_{2} \mathrm{O}_{7}$ and $0.185 \mathrm{mM} \mathrm{MnCl}_{2}$ were prepared in $100 \mathrm{ml}$ volumetric flask; this solution was the background (blank) solution during preparation of AA standard solution. 1 $\mathrm{ml}$ from each extracted sample and $9 \mathrm{ml}$ from the blank solution, a total of $10 \mathrm{ml}$ was taken for each sample 
analysis and incubated for 60 minute. Finally the AA found in the sample was analyzed using a UV-Vis Spectrophotometer [17].

\subsection{Determination of Ascorbic acid by HPLC method}

\subsubsection{Extraction of ascorbic acid}

$0.200 \mathrm{~g}$ of crud extract was weighed and dissolves with $50 \mathrm{ml}$ of $0.5 \%(\mathrm{v} / \mathrm{v})$ ortophosphoric acid and it was mixed. The content of the bottle were shaking under the shaker for 50 minutes at $250 \mathrm{rpm}$ then it was removed from the shaker and $50 \mathrm{ml}$ HPLC grade water was added, then appropriate volume of extract were filtered through $0.45 \mu \mathrm{m}$ syringe filter. The filtrate was transferred in to $2 \mathrm{ml}$ vial and the vial was capped. Finally, the ascorbic acid in the sample was analyzed using HPLC method. Similar procedure followed for other kind of sample.

\subsubsection{Recovery analysis}

In this work, since certified standard reference materials were not available in the laboratory, the validity of the analytical procedures and efficiency of the UV-Vis spectrophotometer and HPLC used for sample analysis was tested by spiking experiment and calculating the recovery percent. Spiking experiment was done to evaluate or check the validity of the extraction procedure and efficiency of the methods used for sample analysis. The spiked samples were analyzed for their respective AA content using UV-Vis spectrophotometer and HPLC method. The calibration curve was obtained by plotting peak area versus concentration for each sample to determine the square of the correlation coefficient $\mathrm{R}^{2}$.

The accuracy of the method was determined by application of the standard addition method and in order to determine the percent recoveries of ascorbic acids in M.stenopetala leave sample. The sample extract was spiked with two known concentration of calibration solutions. For the standard compound, the recovery experiments were carried out with ascorbic acid standard conducting the entire procedure applied for the samples.

The precision refers to the degree of proximity of the results expressible as \% relative standard deviation (RSD) of the retention time and peak area. The repeatability of the retention time and peak areas (Pa) were checked by injecting the mixed standard solutions at two concentration levels into the HPLC system. The RSD of retention time and peak areas were calculated for four replicate determinations [50].The \% recovery was calculated using the formula as follows:

$$
\text { Recovery }(\%)=\frac{\text { Cs in the spiked samples }- \text { Cs in the un }- \text { spiked samples } \times 100 \%}{\text { spiked concentration }}
$$

\section{RESULTS AND DESCUSSION}

\subsection{Physicochemical characterization}

Even though there are many kinds of physicochemical characterizations, in this study $\mathrm{pH}$ and moisture contents of the selected green leaves vegetable sample were studied. The moisture content tells the quantity of water contained in the sample and suggests the concentration of the acid in the sample and $\mathrm{pH}$ was determined for knowing the acidity condition. Table -4.1 Mean of some physicochemical analysis result (mean \pm S.D, $n=2)$ of M.stenopetala leave sample.

\begin{tabular}{|c|c|c|c|c|}
\hline $\mathrm{S} / \mathrm{N}$ & Area M.s sample & Status & $\mathrm{pH}$ & Moisture content $(\%)$ \\
\hline \multirow[t]{2}{*}{1} & \multirow[t]{2}{*}{ Konso } & Fresh & $5.696 \pm 0.646$ & $90.10 \pm 0.131$ \\
\hline & & Cooked & $6.67 \pm 0.452$ & $89.95 \pm 0.221$ \\
\hline \multirow[t]{2}{*}{2} & \multirow[t]{2}{*}{ Arbaminch } & Fresh & $5.673 \pm 0.310$ & $88.33 \pm 1.214$ \\
\hline & & Cooked & $6.14 \pm 0.541$ & $85.23 \pm 1.13$ \\
\hline \multirow[t]{2}{*}{3} & \multirow[t]{2}{*}{ Dilla } & Fresh & $4.813 \pm 0.791$ & $87.54 \pm 1.13$ \\
\hline & & Cooked & $5.91 \pm 0.413$ & $81.75 \pm 1.21$ \\
\hline
\end{tabular}

As Table 4.1 shows, the $\mathrm{pH}$ value of this green leave vegetable sample range from 4.813 to 6.76 (weak acidic media) and the moisture content range from 81.75 to 90.10 . The fresh leave sample from Konso has the maximum moisture content $(90.10 \pm 0.131)$, followed by Arbaminch $(88.33 \pm 1.214)$ and Dilla $(87.54 \pm 1.13)$, respectively. The origin of this variation can be due to difference climatic condition, maturity, storage, harvesting time, and handling during collection. However, The AA contents were related to the amount of the moisture content.

Because weight loss increase with increase temperature due to release water, $\mathrm{CO}_{2}$ and emission of organic compounds. The higher the moisture content (water content), the lowest the AA content is found as described in the literature part [19]. This might be due to the dilution effect. This is not always true for all green leave vegetable. Because the AA content varies from plant to plant due to climate condition, soil condition, time of harvesting [18].

Therefore, the finding of this study suggests that the $\mathrm{pH}$ and the moisture content of Fresh M.stenopetala leave (FMs) Sample are higher than the Cooked M.stenopetala leave (CMs) Sample. This confirms that the AA has a very short half -life in this green leave vegetable due to its highly sensitive for temperature and light. Moreover, in Fresh Ms leave has grater AA content than Cooked Ms leave sample. The present study slightly comparable with reported literature [57]. 


\subsection{Effect of AA on absorbance of $\mathrm{Cr}$ (VI)}

In this study the amount of total AA in selected dietary sources (M. stenopetala leaves) was determined using indirect UV-Vis method through catalytic titration with $\mathrm{Cr}$ (VI). $\mathrm{Cr}$ (VI) was used as UV-vis active material and the determination of AA was based on the decrease in absorbance of the $\mathrm{Cr}$ (VI) solution as a result of its reaction with AA in presence of $\mathrm{Mn}(\mathrm{II})$. When the $\mathrm{Cr}$ (VI) reacts with AA in the presence of Mn (II), it was reduced and gradually eliminated from the reaction. Thus, a solution containing $\mathrm{Cr}$ (VI) and $\mathrm{Mn}$ (II) in appropriate proportion served as a background (blank) solution in which ascorbic acid is dissolved to prepare standard solutions. Since reduction of $\mathrm{Cr}$ (VI) by AA alone is very low [53], Mn (II) was used to catalyze the reduction of Cr (VI); it caused a time dependent decrease of $\mathrm{Cr}$ (VI) absorption signal when AA, Mn (II) is present. What happens to the absorbance of the background solution when incubated in presence and absence of AA was a key question to answer. Therefore, the absorbance of two solutions (solution 1: background solution containing $0.335 \mathrm{Cr}$ (VI) and $0.185 \mathrm{mM} \mathrm{Mn}$ (II); solution 2. A solution of $0.05 \mathrm{M}$ AA prepared in the background solution). Background Solution 1 and 2 differ only in absence or presence of AA. The molar ratio of the Cr (VI) to Mn (II) was 0.335:0.185 mM in both solutions. The two solutions were incubated for different period of time at ambient and absorbance were continuously monitored. The result was indicated in Figure 4.1. Figure 4.1 (a) shows the absorbance of background solution containing $0.335 \mathrm{Cr}$ (VI) and $0.185 \mathrm{mM} \mathrm{Mn}$ (II) against different reaction time. Whereas Figure 4.1 (b) shows the absorbance of the background solution containing $0.05 \mathrm{M} \mathrm{AA}$.

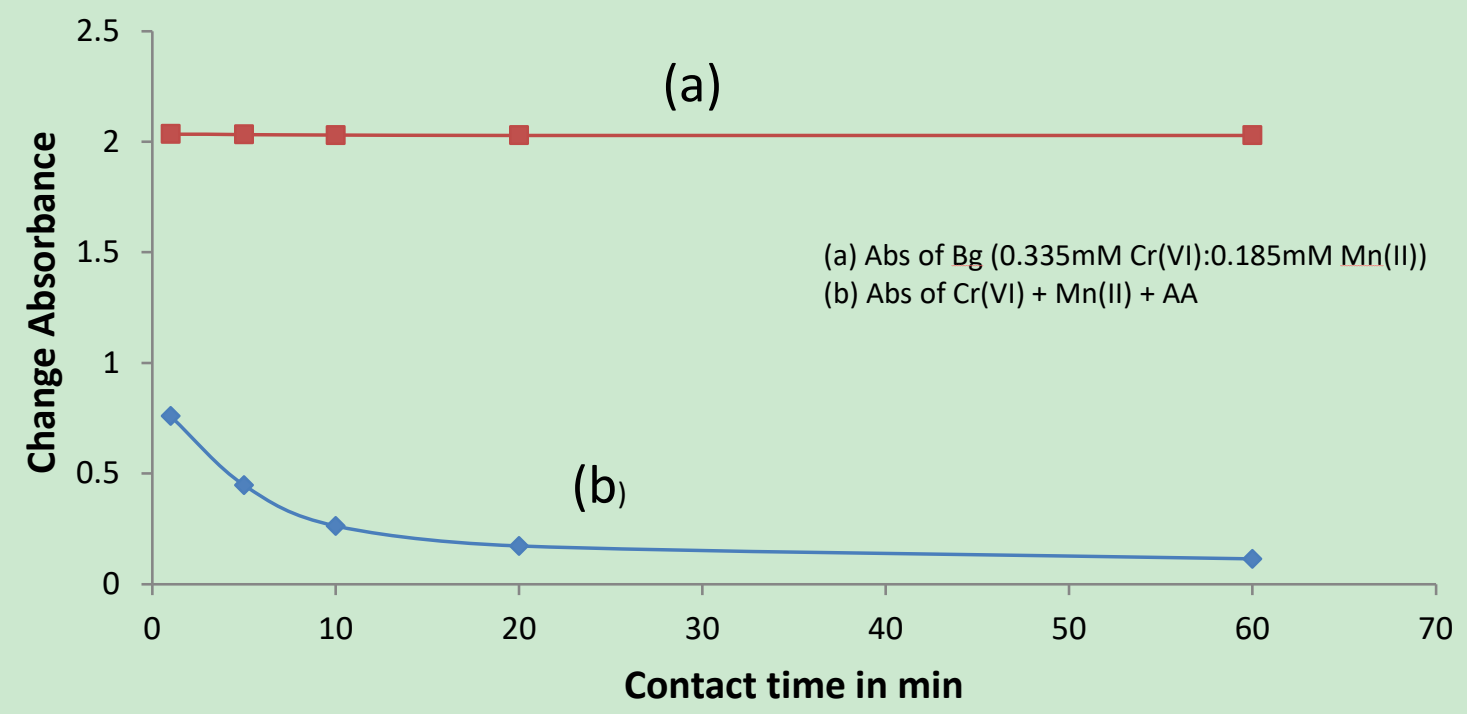

Figure 4.1Change in absorbance against different incubation time of background solution presence or absence of Ascorbic acid.

As Figure 4.1 shows (a) the absorbance of the background solution remained constant as the reaction time increased from 10-70 minute. However, the absorbance of the background solution containing AA (0.05M) decreased as the incubation time increased (Figure 4.1 (b)). This shows that AA had a significant effect on absorbance of $\mathrm{Cr}$ (VI) in the presence of Mn (II). That means, decrease in absorbance of $\mathrm{Cr}$ (VI) in the presence of AA indicate that, reduction of $\mathrm{Cr}$ (VI) by AA through a time. It was used as a reducing agent; can reduce $\mathrm{Cr}$ (VI) in the presence of Mn (II). The next important thing is to test whether the observed change in absorbance is quantitatively related to concentration of AA.

\subsection{UV-Vis determination of Ascorbic acid and calibration curve}

The effect of concentration of AA on the decrease in the absorbance of $\mathrm{Cr}$ (VI) solution was investigated by carrying out the reaction using different standard concentrations of AA prepared in a background solution containing Cr (VI) and Mn (II) in 0.335:0.185 $\mathrm{mM}$ ratio. The absorbance was recorded at $350 \mathrm{~nm}$. Then, the absorbance of the background solution in the absence and presence of AA was measured and recorded. Calibration curve of change in absorbance against standard concentrations of AA was constructed using $0.335 \mathrm{mM} \mathrm{Cr}(\mathrm{VI})$ : $0.185 \mathrm{mM} \mathrm{Mn}(\mathrm{II})$ as background solution used to prepare standard AA solutions of concentration $0.0001,0.001$, $0.005,0.01,0.025$ and $0.05 \mathrm{M}$.

A linear relationship was observed between change in absorbance of the background solution in the presence of $\mathrm{AA}$ in the range of 1.98 to 0.08 (Figure 4.2). The linear regression equation of $y=37.65 \mathrm{x}+0.095$ with $\mathrm{R}^{2}=$ 0.998 was recorded. Finally the amount of AA in the sample was determined from the calibration curve. The result is indicated in Figure 4.2.

The values of LOD and LOQ $(n=2)$ were determined as the analyte concentration corresponding to 3 times of the standard deviation of the reagent blank $\left(3 S_{B} /\right.$ slope $)$ divided by slope of the calibration curve(LOD) and 10 
times standard deviation (SD) divided by the slope of the calibration curve (LOQ). The performance of the method was evaluated on the basis of the validation results. The LOD and LOQ were 0.00154 and $0.005134 \mathrm{mg} / \mathrm{ml}$, respectively. This calculated from the blank response.

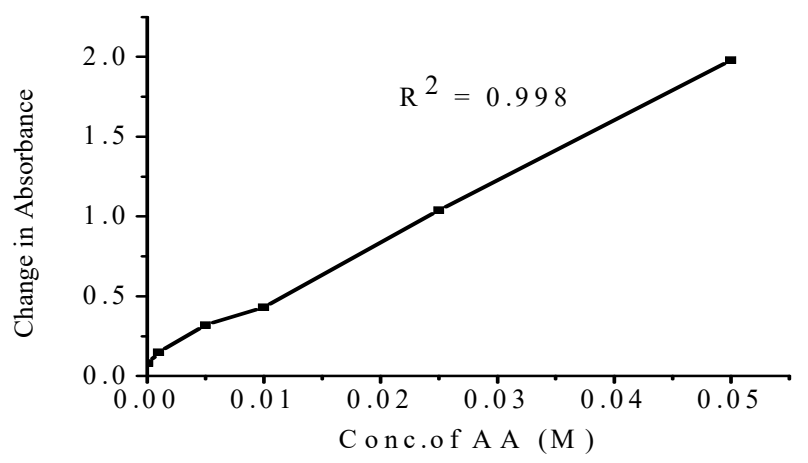

Figure 4.2 Calibration curve of change in absorbance of $\mathrm{Cr}$ (VI) solution against standard concentrations of AA.

Since the reduction efficiency of $\mathrm{Cr}(\mathrm{VI})$ by AA depends on different experimental variables such as the concentration ratio of oxidant and catalyst; $\mathrm{Cr}$ (VI): $\mathrm{Mn}(\mathrm{II})$, reaction time or incubation time and $\mathrm{pH}$ conditions, optimization of experimental variables were performed on concentrations of AA in presence of Mn(II).

\subsection{Optimization of experimental variables during $\mathrm{UV}-\mathrm{V}$ is analysis}

\subsubsection{Effect of concentration of oxidant and catalyst; (Cr (VI): Mn (II)}

According to Beer's law, UV-Vis instrument may not be applied to all concentration ranges. The law only works at low concentration (mM). So, fixing the concentration of the oxidant and catalyst; $\mathrm{Cr}$ (VI): Mn (II) ratio was valid in order to get fast reduction of $\mathrm{Cr}$ (VI) by AA. It was studied by fixing the catalyst and increasing the oxidant from $0.335: 0.185$ to $0.67: 0.185$, fixing the oxidant and increasing the catalyst from $0.67: 0.185$ to $0.67: 0.37$, fixing both the oxidant and catalyst from $0.67: 0.37$ to 0.335 to 0.185 and by dilution of oxidant/catalyst with distilled water $(0.0335: 0.0185)$. The $\mathrm{pH}$ was adjusted to $3-5$ with $\mathrm{H}_{3} \mathrm{PO}_{4}(88 \%$ pure $)$ using a digital $\mathrm{pH}$ meter. The result is indicated in Figure 4.3. It shows the absorbance of background solution against different concentrations of AA prepared in solutions of varying proportions of $\mathrm{Cr}$ (VI) and Mn (II) [53].

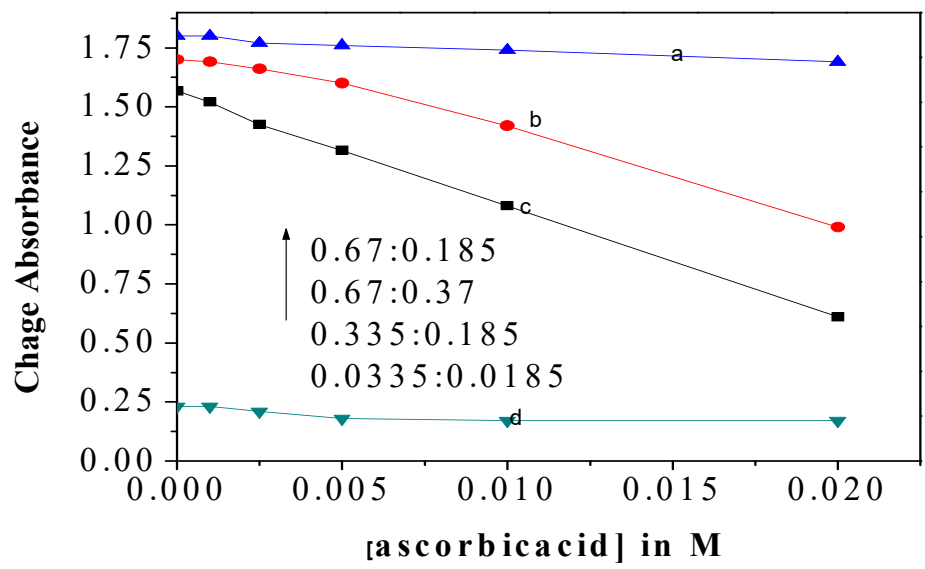

Figure 4.3 Figure 4.3 Effect of $\mathrm{Cr}$ (VI) to Mn(II)proportion on absorbance reduction by AA.

It was found that the $0.335: 0.185$ oxidant/catalyst ratios showed the best reduction of $\mathrm{Cr}$ (VI) while AA concentration was increased from 0.0 to $0.02 \mathrm{M}$. This is evident from the slope of the curve that reflects rate of reaction. When fixing the oxidant and increase the catalyst from 0.67:0.185 to 0.67:0.366, the absorbance reading was nearly constant from 0.0 to $0.0001 \mathrm{M}$ of AA but after $0.0001 \mathrm{M}$ of AA, littlie decrement of absorbance was observed.

In case of 0.67:0.183 oxidant/catalyst ratios, the $\mathrm{Cr}(\mathrm{VI})$ was reduced in some extent but complete reduction was not observed. However, faster reduction of $\mathrm{Cr}(\mathrm{VI})$ was observed in 0.335:0.183 $\mathrm{mM}$ oxidant/catalyst ratio; the absorbance result was decreased gradually (almost the reduction was completed after concentration of $0.015 \mathrm{M}$ AA) as concentration of increased and assured linearity of the calibration curve with correlation coefficient of 0.998. Diluting 0.335:0.185 oxidant/catalyst ratios to 0.0335:0.0185 oxidant/catalyst ratios, the absorbance result became small and nearly constant when compared to the other background ratios; the $\mathrm{Cr}$ (VI) was completely reduced or eliminated from the AA solution and it became the limiting reagent. These confirm that, 0.335:0.185 
oxidant/catalyst ratios were the best background ratio.

\subsubsection{Effect of reaction time on the reduction of $\mathrm{Cr}(\mathrm{VI})$}

When AA was reacted with $\mathrm{Cr}$ (VI) in the presence of $\mathrm{Mn}(\mathrm{II})$, the reduction efficiency of $\mathrm{Cr}(\mathrm{VI})$ depended on reaction time (incubation time). Fixing the reaction time for a near completion of the reaction was valid. First the background solution and background solution containing AA were prepared and incubated for 20, 30, 45, 60 and 90 minutes and absorbance measurements were performed for each time. The result is indicated in Figure 4.4.

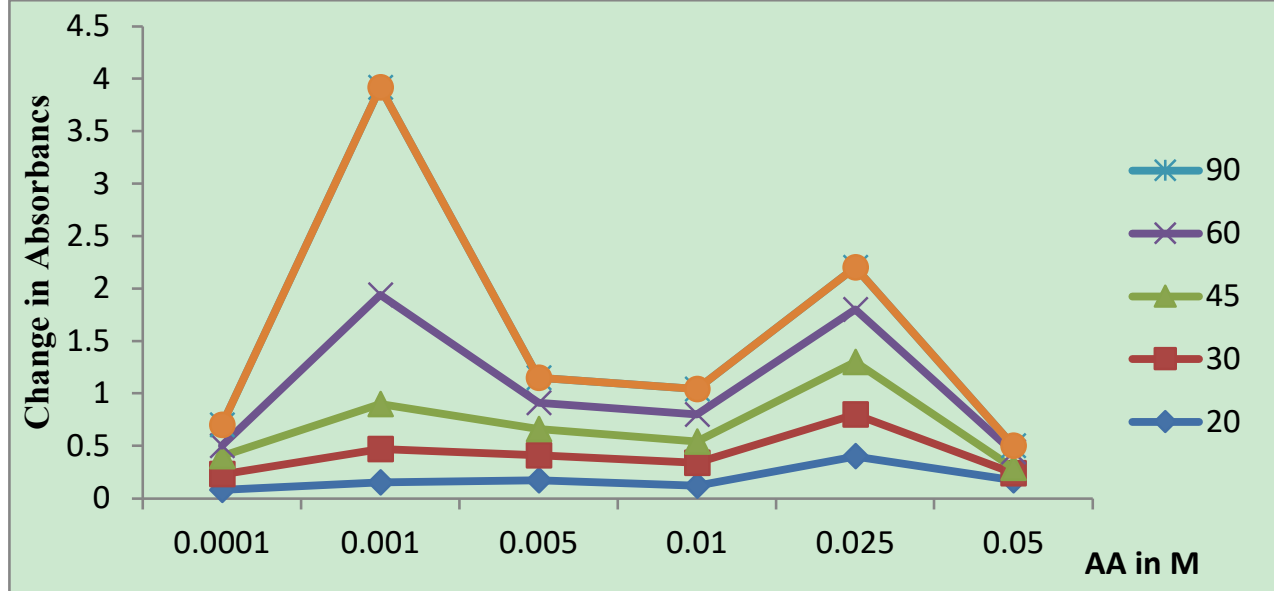

Figure 4.4 Effect of reaction time on reduction of $\mathrm{Cr}$ (VI) by AA

As can be seen in Figure 4.4, the reduction of $\mathrm{Cr}$ (VI) was related to the slope of calibration curve and the reaction time. As the reaction time increased, the decrease in $\mathrm{Cr}(\mathrm{VI})$ absorbance as a function of becomes sloppier. Within the first $20 \mathrm{~min}$ of the reaction, the reduction rate of $\mathrm{Cr}$ (VI) was very slow initially. The absorbance of the background solution in the absence and presence of AA was nearly constant over the reaction time and it was less sloppy (lees reduction efficiency). That means the extent of reaction was low to cause a detectable reduction in absorbance. After the reaction for 45 minutes, reduction of $\mathrm{Cr}(\mathrm{VI})$ was recorded by observed significant reduction in absorbance; the absorbance decreased and the graph became sloppier than previous one. Incubation after 60 minute, the absorbance linearly decreased; the linearity of the calibration curve was assured. However, the residual concentration of $\mathrm{Cr}(\mathrm{VI})$ reached almost zero in 90 minutes. Even though, the calibration curve of all measurements showed reduction of $\mathrm{Cr}(\mathrm{VI})$, the best reduction was observed after 60 minute where a sensitive detection can be made. Therefore, 60 minute was selected as an optimum time in order to study the significant effect of AA on absorbance of $\mathrm{Cr}$ (VI) in the presence of $\mathrm{Mn}$ (II).

\subsubsection{Effect of $\mathrm{pH}$ on the reduction of $\mathrm{Cr}$ (VI) by $\mathrm{AA}$}

In order to know the optimum $\mathrm{pH}$ at which a sensitive detection of AA via its reaction with $\mathrm{Cr}$ (VI) can be made, the reaction mixture was incubated at $\mathrm{pH}$ of 1.5,3 and 5. The result is indicated in Figure 4.5.

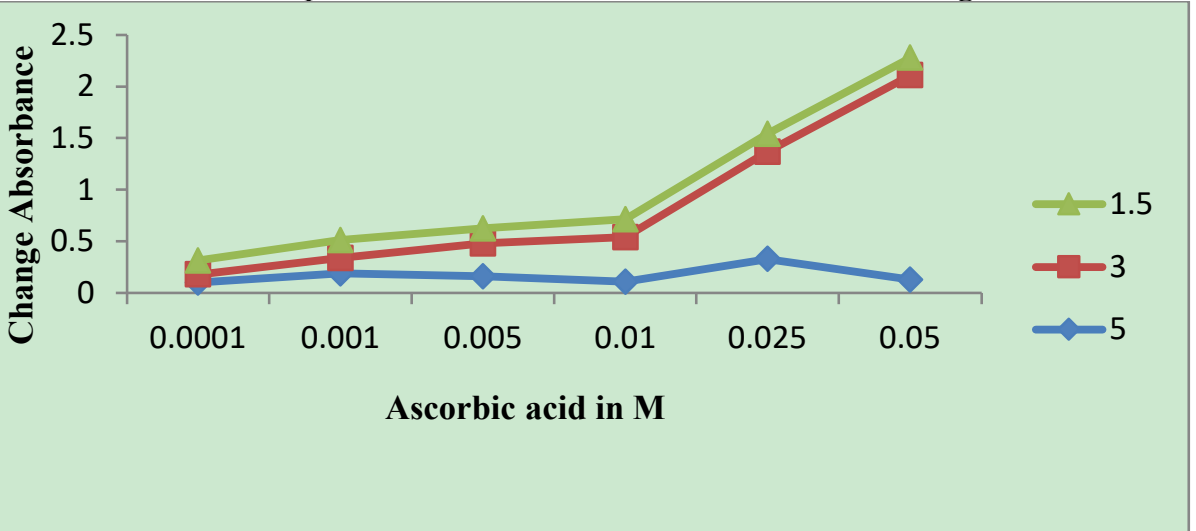

Figure 4.5 Effect of $\mathrm{pH}$ on $\mathrm{Cr}(\mathrm{VI})$ reduction by AA

As indicated in Figure 4.5, the $\mathrm{pH}$ value had a significant effect on reduction of $\mathrm{Cr}$ (VI) by AA in the presence of $\mathrm{Mn}$ (II). The result from effect of $\mathrm{pH}$ on the reduction of $\mathrm{Cr}$ (VI) indicate reduction of $\mathrm{Cr}$ (VI) might occur in weakly alkaline solution ,however, the reaction efficiency increased in acidic conditions, in addition to this, It is important to point out that $\mathrm{Cr}(\mathrm{VI})$ could be reduced by AA in the weakly acidic solutions ( $\mathrm{pH} 3-5)$. The reduction rate of $\mathrm{Cr}(\mathrm{VI})$ by AA obviously increased with decreasing $\mathrm{P}^{\mathrm{H}}$. The optimum $\mathrm{P}^{\mathrm{H}}$ range was 3-5.

\subsection{Interference study}

To study the selectivity of the proposed method, the effect of potential interfering substances that could exist in 
the studied selected green leafy vegetable samples were considered. For this purpose, MA and OA was considered because of its presence in most green leave vegetables [54,55]. In both the effect of MA and OA on the absorbance of the $\mathrm{Cr}$ (VI) and AA mixture was studied by recording absorbance of $\mathrm{Cr}$ (VI) and AA mixture in presence and absence of MA and OA.

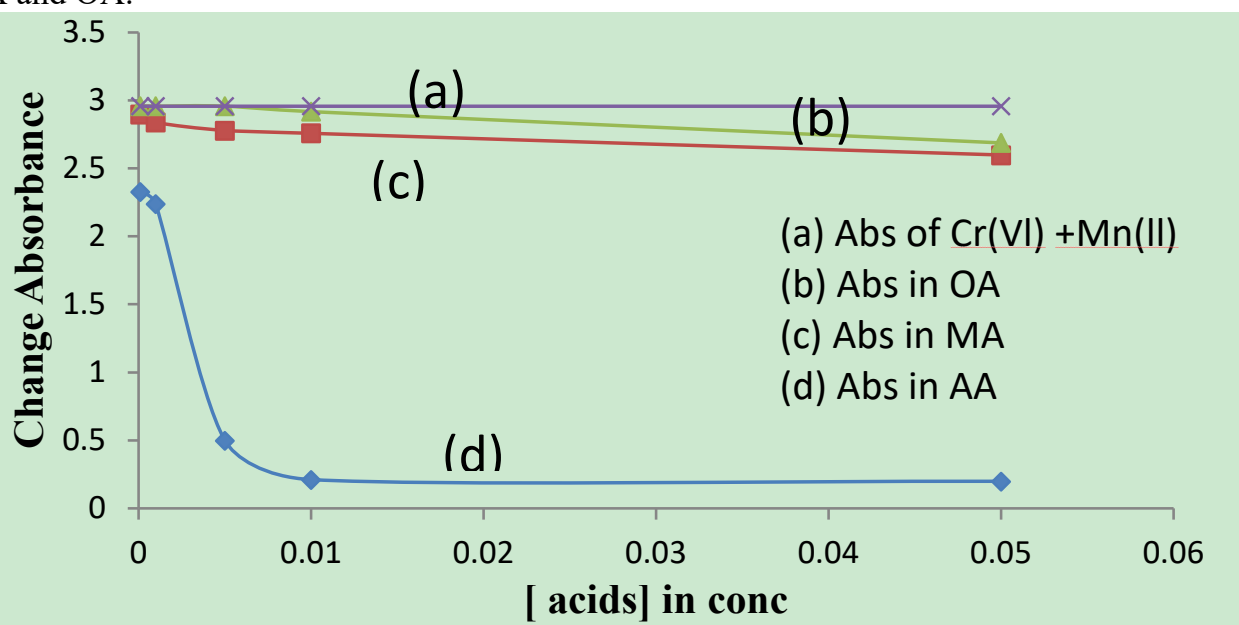

Figure 4.6 Effect of interference AA, MA and OA on absorbance of $\mathrm{Cr}$ (VI) and absorbance of back ground solution

The result showed that practically no effect of weather MA or OA on the reaction mixture as recorded by lack of difference in the absorbance. However, the expected reduction in the absorbance of the $\mathrm{Cr}$ (VI) due to its reaction was observed regardless of the presence or absence of MA and OA. Reduction of Cr(VI) by MA and OA less as compared with reduction by AA at $60 \mathrm{~min}$, therefore AA determine with less interference. Moreover, Only a small change between the absorbance could be observed when $1 \mathrm{mM}$ MA and OA was incorporated in the mixture. The reduction in absorbance of $\mathrm{Cr}(\mathrm{VI})$ due to $1 \mathrm{mM}$ AA was 0.221 respectively after 60 minute reaction time. The absorbance of the same reaction mixture but also containing $1 \mathrm{mM}$ MA and OA showed absorbance reduction of $0.219,0.220$, respectively. This implies that in the presence of $1 \mathrm{mM}$ MA and OA could cause a difference of 0.002 , 0.001 in absorbance, respectively. Therefore, it can be concluded that the modified method can be successfully applied for the detection of AA in the presence of other interfering species.

\subsection{Application of the method for determination of AA in M.stenopetala leaves}

The ascorbic acid content of M.stenopetala leaves sample was quantified using the indirect UV-vis spectrophotometer through catalytic titration method. The results are presented in (Table 4.2). Samples were extracted according to the procedure described. The crud extract was dissolved in the given solvent and reacted with the background solution and absorbance of the background solution and the solution containing the extract was recorded after incubation for 60 minutes. The change in absorbance was used along with the linear regression equation to determine the concentration of $\mathrm{AA}$ in the samples. All determinations were done in triplicate. The result is summarized in Table 4.2. The maximum average concentration of AA was recorded in FMsA (237.003 \pm 0.0010$)$ followed by FMsK $(233.023 \pm 0.0017) \mathrm{mg} / 100 \mathrm{~g}$. The lowest concentration of AA was recorded at FMsD which was $(211.012 \pm 0.0148) \mathrm{mg} / 100 \mathrm{~g}$. When compared to the Fresh and Cooked samples, the highest concentration of AA was found in the Fresh Ms $(237.003 \pm 0.0010) \mathrm{mg} / 100 \mathrm{~g}$ rather than cooked Ms $(209.021 \pm$ $0.0179) \mathrm{mg} / \mathrm{g}$. the reason it might be, being vitamin $\mathrm{C}$ sensitive to heat and oxygen, it is rapidly oxidized, Therefore, this study aligns with the level of AA content reported literature by [59].Table 4.1 Average value of AA concentration in green leafy vegetable samples (Mean \pm S.D, $n=2$ ).

\begin{tabular}{|c|c|c|c|c|c|}
\hline $\mathrm{S} / \mathrm{N}$ & Area & $\begin{array}{l}\text { Common } \\
\text { names }\end{array}$ & Status & $\begin{array}{l}\text { Abbreviated } \\
\text { name }\end{array}$ & $\begin{array}{l}\text { Ascorbic } \begin{array}{l}\text { acid } \\
\text { concentration }(m \mathrm{~g} / 100 \mathrm{~g})\end{array}\end{array}$ \\
\hline \multirow[t]{2}{*}{1} & \multirow[t]{2}{*}{ Konso } & \multirow[t]{2}{*}{ M.stenopetala } & Fresh & FMsK & $233.023 \pm 0.0017$ \\
\hline & & & Cooked & CMsK & $208.043 \pm 0.0017$ \\
\hline \multirow[t]{2}{*}{2} & \multirow[t]{2}{*}{ Arbaminch } & \multirow[t]{2}{*}{ “" } & Fresh & FMsA & $237.003 \pm 0.0010$ \\
\hline & & & Cooked & CMsA & $209.021 \pm 0.0079$ \\
\hline \multirow[t]{2}{*}{3} & \multirow[t]{2}{*}{ Dilla } & \multirow[t]{2}{*}{ “6 } & Fresh & FMsD & $211.012 \pm 0.0048$ \\
\hline & & & Cooked & CMsD & $204.042 \pm 0.0097$ \\
\hline
\end{tabular}

As the data in Table 4.2 indicates for these sample the concentrations of AA studied along the fresh M.stenopetala leaves sample showed a significantly vary in concentration as compared to Cooked M.stenopetala leave sample and this Phenomena or variation which happened it might be due to the effect of temperature and light an increase in membrane permeability which allows acids to be stored in the respiring cells, formation of 
complex salts of AA, reduction in the amounts of acid trans located from the leaves, reduced ability of leave to synthesize organic acids with leave maturity, translocation into sugars and dilution effect due to the increase in the volume of leave as previously reported in the literature [23].

Therefore, the maximum concentrations of AA in Fresh M.stenopetala leave (FMs) were recorded in Arbaminch $(237.002 \pm 0.0010 \mathrm{mg} / 100 \mathrm{~g})$ and the minimum concentration of AA recorded in Dilla $(211.012 \pm 0.0148$ $\mathrm{mg} / 100 \mathrm{~g}$ ). there were significance difference in the value obtained for AA in FMs(data shown in Table 4.2). These Phenomena indicated that cooking can reduce the level of AA in these green leafy vegetable.

\subsection{Effect of cooking on AA}

In order to study the level of AA loss from the fresh Ms Sample to cooked Ms Sample and to investigate whether household cooking method might be reduction of AA at the given time interval, analysis was performed on vegetable sample using UV-Vis spectrophotometer. First the weight of the sample that was going to be analyzed before and after cooking was recorded. Then Percentage of AA loss due to cooking was calculated as $100-\%$ TR (True Retention)[56].

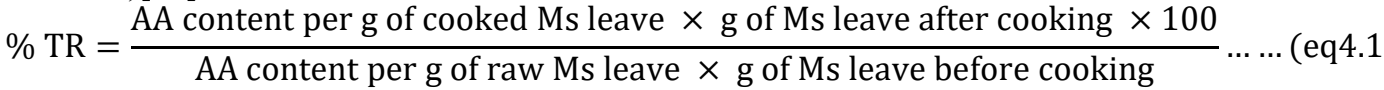

The true retention; the amount of AA remained in the M.stenopetala leaves sample and after cooking by boiling ten minute were calculated using the above formula. The percentage of true retention value for MsA, MsK and $\mathrm{MsD}$ were $59.79 \%, 51.23 \%$ and $47.74 \%$ respectively. The percentage of AA loss was $40.21 \%, 48.77 \%$ and $52.26 \%$ respectively. These data recommend that household cooking is a significantly reduced total AA level in this green leave vegetable (Ms) sample. Because of this the decrease in mass of the crude extract on Cooking Ms leave may also suggest possible existence of other compounds such as chlorogenic acid that could be together with AA. Such compound may be decomposed up on cooking this could be the reason to obtain highest percentage AA lost or lowest mass of crude AA extract from the cooked Ms Leave sample.

Moreover, in this experiment, boiling of the Ms Leave sample for a relatively short time (10 $\mathrm{min}) \mathrm{had}$ significant effect on the reduction of total AA content of the Ms Leaves. This phenomenon is consistence to the study reported by [56] who observed a $33.5 \%$ loss of AA when the purslane leaves were cooked for 10 min in boiling water and allowed to drain for 5 minute. Studies on other vegetables have shown that boiling an AA reach plant allows it to lose total AA into the cooking water; [57] was reported that boiling resulted in significant loss of total AA of some New Zealand foods such as spinach (Spinaciaoleracea), silverbeet (Beta vulgaris v.cicla) and rhubarb (Rheum rhaponticum). A recent study reported losses of AA between 38 and $87 \%$ from various vegetables such as spinach, Swiss chard and Brussels sprouts boiled their vegetable for 12 minute. When the purslan was boiled for $25 \mathrm{~min}$ and this resulted in a significant decrease of total AA levels [58], however, this treatment also resulted in an undesirable loss of total solids and valuable nutrients. It seems unlikely that boiling purslane for such a long time will allow it to retain its health benefits. Similar findings appeared in total AA, significant loss ranged from 30\% in cooked white stems swamp morning glory (Lpomoeaaquatica, Forsk) to $83 \%$ in cultivated bamboo shoot (Bambusa spp.). Therefore, AA has a very short half- life in M.stenopetala Leaves collected in this analysis were cooked, the AA showed significantly decrease than that which would be found in fresh Ms leaves due to cooking by boiling.

\subsection{Accuracy of the method}

Method accuracy or validity was tested by recording recovery of spiked amount of AA in the crude extract of M. stenopetala leave samples. Taking into account that, there is no appropriate reference material containing AA in Ms Leave samples analyzed, a recovery test was carried out. The volume of spiking solution is calculated as:

$$
\begin{gathered}
\text { Volume of spike to add }=\frac{\text { choosen spike conc. } \times \text { Extraction volume(sample volume) }}{\text { Concentration of stock }(\text { spiking) solution }} \\
\text { Volume of spike to add }=\frac{0.01 \mathrm{mg} / \mathrm{ml} \times 100 \mathrm{ml}}{0.1 \mathrm{mg} / \mathrm{ml} /}=10 \mathrm{ml}
\end{gathered}
$$

The volume of the spike was added to the $100 \mathrm{ml}$ sample and the extract crud samples at two different concentration levels $(0.01$ and $0.1 \mathrm{mg} / \mathrm{ml}$ of AA) and First the absorbance of the samples concentration (un-spiking) was detected by using UV-vis sphectophotometry followed by the absorbance of spiked sample. analyzed in triplicate using UV-Vis Spectrophotometric method in this study. The results of the recovery experiments are shown in Table 4. 3, The Standard stock solution of the AA used as a spiking solution. The amount of spike concentration was $0.01 \mathrm{mg} / \mathrm{ml}$. Then it was detected using UV-Vis Spectrophotometric method and the concentration of spike plus sample was recorded. The \% recovery was calculated using the formula as follows:

$$
\text { Recovery }(\%)=\frac{\text { Cs in the spiked samples }- \text { Cs in the un }- \text { spiked samples } \times 100 \%}{\text { spiked concentration }}
$$

Where, $\mathrm{C}_{\mathrm{s}}=$ concentration of AA in each sample of interest. The results were indicated in Table 4.3. 
Table 4.2 Recovery test for the extraction procedure crude extract of M.stenopetala leave sample.

\begin{tabular}{|c|c|c|c|c|c|}
\hline $\begin{array}{l}\text { Sample } \\
\text { status }\end{array}$ & $\begin{array}{l}\text { Area of the } \\
\text { sample }\end{array}$ & $\begin{array}{l}\text { a Concentration in un- } \\
\text { spiked sample (M) }\end{array}$ & $\begin{array}{l}\text { Amount } \\
\text { added } \\
(\mathrm{M})\end{array}$ & $\begin{array}{l}\text { a Concentration in } \\
\text { spiked sample (M) }\end{array}$ & ${ }^{\mathrm{b}}$ Recovery $\quad(\%)$ \\
\hline FMsK & Konso & $0.0085 \pm 0.003536$ & 0.01 & $0.0189 \pm 0.090$ & $100 \pm 0.0048$ \\
\hline CMsK & " & $0.0073 \pm 0.001414$ & 0.01 & $0.0167 \pm 0.093$ & $94 \pm 0.0047$ \\
\hline FMsA & Arbaminch & $0.0118 \pm 0.003536$ & 0.01 & $0.0218 \pm 0.086$ & $100 \pm 0.0034$ \\
\hline CMsA & " & $0.0089 \pm 0.002828$ & 0.01 & $0.0183 \pm 0.082$ & $94 \pm 0.0042$ \\
\hline FMsD & Dilla & $0.0128 \pm 0.000707$ & 0.01 & $0.0214 \pm 0.037$ & $86 \pm 0.019$ \\
\hline CMsD & " & $0.0099 \pm 0.002828$ & 0.01 & $0.0189 \pm 0.083$ & $90 \pm 0.042$ \\
\hline
\end{tabular}

${ }^{a}$ Concentration values are average of two analyzed samples \pm standard deviation.

${ }^{\mathrm{b}}$ Recovery values are mean \pm standard deviation.

Table 4.3 indicates that the recorded percentage recoveries for the studied AA in M.stenopetala leave samples lied within the range $86-100 \%$, this mean that it is in the acceptable range $(80-115 \%)$. This confirms that, the laboratory performance for each analyte is in control and the optimized extraction procedure is valid, accurate and reproducible. Therefore, the modified method can be successfully applied for the valid and accurate determination of AA in M.stenopetala leave sample.

\subsubsection{HPLC analysis of AA standards}

Even though UV-Vis spectrophotometer was used for determination of AA in green leave vegetable sample, it has its own limitations such as less sensitive and can't detect analyte having large concentration. To improve these limitations and further validate the modified UV-Vis method using standard method, hyphenated HPLC (HPLCVWD/DAD) method was used, which is sensitive, reliable, selective and separate interferences. A Major advantage of HPLC is that it can be used in preparative mode and actually separate out mixtures to give pure compounds that can be detected by the detector.

In this study AA standard solution was analyzed using chromatographic conditions. the chromatographic condition which was leveled as used for analyzing the FMsK and FMsA. All HPLC analyses were carried out at JIJE Analytical Testing Service Laboratory, Addis Ababa Ethiopia. The standards and the samples were run in the HPLC system using the HPLC machine (Agilent 1260 equipped with G1310B pump, G1316A column compartment, G1329B auto sampler and G4286B detector (VWD)). The following table (Table-4.4) shows the parameters or the HPLC conditions that have been used during the experiments.

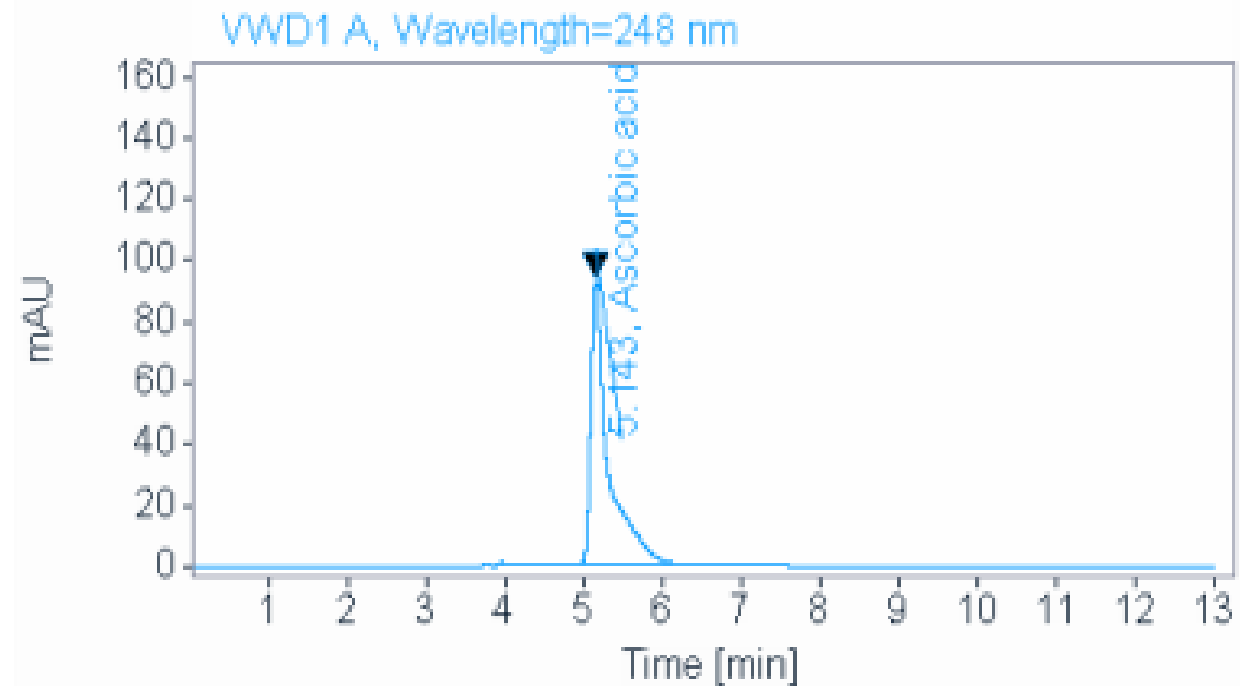

Figure 4.6 Chromatogram of standard for analyzing M.stenopetala leave sample

As Figure 4.6 indicates, the chromatographic peak for the AA standard solution was eluted with a retention 
time of 5.143 minute. These suggested that, at this retention time of the sample peak also expected to elute.

\subsubsection{Standard calibration for analyzing M.stenopetala leave sample}

The area of each peak could be used to determine the amount of AA present in the Ms (quantitative analysis) as long as a calibration curve was prepared first relating the peak area to the concentration of the analyte were contracted under chromatographic condition. All standard solutions were filtered through a $0.45 \mathrm{~mm}$ syringe filter prior to analysis using HPLC system. The standard curve for ascorbic acid extraction was constructed by preparing a series of standard solutions of $99.99 \%$ ascorbic acid with concentrations of $10,20,40$ and 60 ppm in $0.5 \% \mathrm{H}_{3} \mathrm{PO}_{4}$ (ortophosphoric acid) and their observed peak areas increase with the concentration were found to be 158.883, $385.115,880.121$ and 1433.331 for $10,20,40$, and $60 \mathrm{ppm}$ solution, respectively. This confirm that, Calibration curve of Peak area vs Concentration of working standards was constructed to validate the HPLC quantification of AA in terms of linearity, sensitivity, and precision. The linearity of the method was evaluated according to peak area response of the standard solution. The standard curves were plotted to compute the regression equations and the concentration of AA from each sample solution was calculated from the equation of the corresponding standard calibration curve. The result is indicated in Figure 4.7.

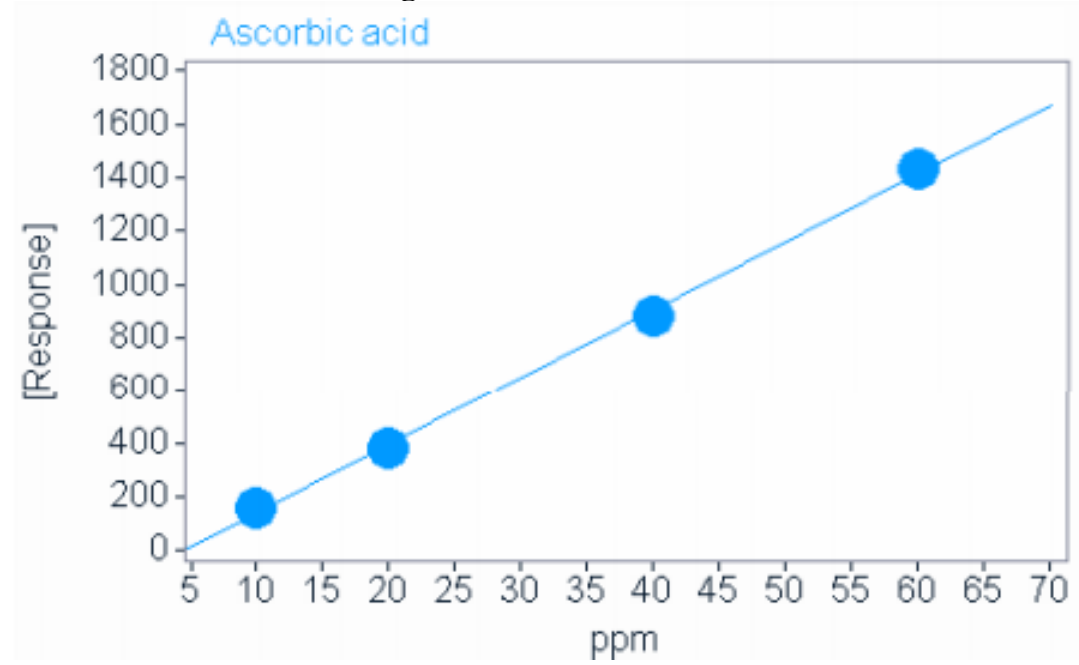

Figure 4.7 Standard calibration curves for the determination of concentration of AA in the M.stenopetala leave samples.

The selected HPLC conditions showed the linear relationship with linear regression equation $\mathrm{Y}=25.510 \mathrm{x}-$ 114.745; A calibration graph was made for the concentration range of standard AA solution from 10 to $60 \mathrm{mg} / \mathrm{L}$ with RSD $1.85 \%$ and correlation coefficient of greater than 0.999 between the peak areas and concentrations of ascorbic acid. Where $\mathrm{Y}$ is peak area, $\mathrm{X}$ is concentration of AA (ppm) and R is the linear correlation factor. Hence, the standard method has taken as suitable and reproducible for the quantitative determination of AA from crude ascorbic acid extracts of Ms Leave samples. The performance of the method was evaluated on the basis of the validation results. The LOD and LOQ were $0.05,0.17 \mathrm{mg} / \mathrm{L}$, respectively. This calculated from the blank response.

\subsection{Detection of $A A$ in real samples}

The level of AA in M.stenopetala sample was determined using the standard calibration curves discussed above. HPLC methods are the most common, reliable methods for the determination AA in complex samples. Very low concentration of AA can also be determined with high accuracy and precision using HPLC. The validated method (of the experiment) was used to determine the AA contents of the Ms leave samples by injecting the solutions prepared from crude AA extracts of the Ms leave samples used in the study. The first samples injected into the machine were the solutions of Arbaminch and Konso raw Ms Leave samples. The result (Chromatogram) indicated that the crude extracted from raw Ms Leave sample gave AA peaks observed at retention times of 4.855 and 4.856 minutes (Fig- 4.8 and Fig- 4.9) for Konso and Arbaminch Ms Leaves Sample, respectively. 


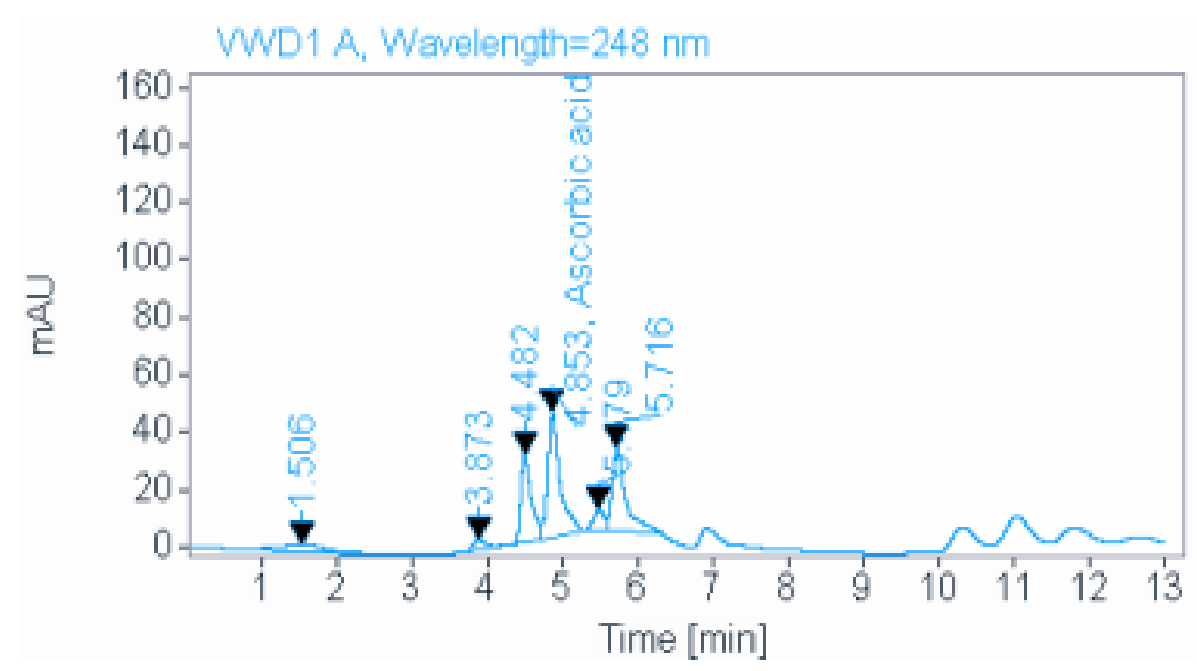

Figure-4.8 the chromatogram peak for FMs Leave sample from Konso.

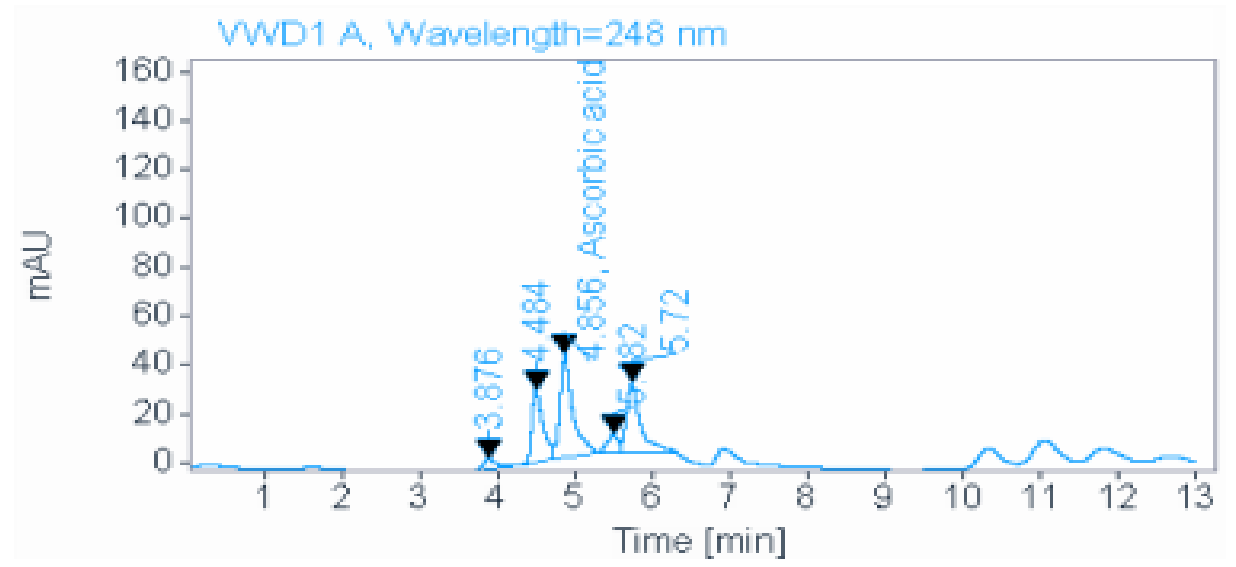

Figure-4.9 the chromatogram peak for FMs Leave sample from Arbaminch.

The AA content obtained from Arbaminch Fresh Ms Leave sample was $239.96 \pm 0.00121 \mathrm{mg} / 100 \mathrm{~g}$ (Table 4.2). In the case of crude AA solution which was extracted from konso Fresh Ms Leave sample was $237.49 \pm 0.00310$. Therefore, the chromatograms indicated that the AA content of Arbaminch Freeh (raw) Ms leave sample was generally higher than that of Konso Ms leave sample.

The results of the AA content in Fresh Ms leave are indicated in Table 4.2.

\begin{tabular}{|l|l|l|l|l|}
\hline S/N & Type and Area of sample & Status & $\begin{array}{l}\text { Abbreviated } \\
\text { name }\end{array}$ & $\begin{array}{l}\text { Concentration of AA } \\
(\mathrm{mg} / 100 \mathrm{~g})\end{array}$ \\
\hline 1 & M.stenopetala from Konso & Fresh & FMsK & $237.47 \pm 0.0310$ \\
\hline 2 & M.stenopetala from Arbaminch & Fresh & FMsA & $239.96 \pm 0.0121$ \\
\hline
\end{tabular}

Values are expressed as mean \pm standard deviation of duplicate analysis.

The maximum concentration of AA was found in Fresh M.stenopetala leave from Arbaminch (FMsA) which was $239.96 \pm 0.0121 \mathrm{mg} / 100 \mathrm{~g}$. Followed by The lowest concentration of AA was found in Konso (FMsK) which is $237.47 \pm 0.0310 \mathrm{mg} / 100 \mathrm{~g}$. This small variation may be due to: geographical origins (different altitude, soil type, rain fall),agricultural practices, environmental conditions, post harvesting processing techniques; grinding size, analytical techniques, extraction method and matrix effect which absorbed by instruments[59].

In general, the concentrations of AA studied along Fresh Ms leave sample showed a decrease in AA concentration (Table 4.6 and 4.2) when compared to the FMsA, FMsK and FMsD leave sample respectively as much as like reported in the earlier study (UV-Vis spectrophotometer study). However the proximate properties obtained in this study did not different significantly from the levels reported literature.

Moreover, Fugile and Seraje et al [60] in philipines reported higher content of AA (16.3ppm) in Moringa oleifera. According to Unhenna Mabel.N et al. [61] and Gholamreza Asghari et al [62] observed that M.pregina leave content sufficient amount of AA $(0.36$ and $83 \mathrm{mg} / 100 \mathrm{~g})$ respectively. Khondoker S. et al.[63] reported that higher content of AA $(228 \mathrm{mg} / 100 \mathrm{~g})$ in Moringa oleifera. On the other hand, the present study obtained $(239.96 \pm 0.0121 \mathrm{mg} / 100 \mathrm{~g})$ AA content in Ethiopia Ms Leave. According to Ramachandran et al [64] reported that 
in the Moringa oleifera is an interesting source of vitamin C. Fresh Moringa leaves contain approximately 200 $\mathrm{mg} / 100 \mathrm{~g}$, greater than orange [65]. Therefore, these amounts are of particular interest, as the vitamin C intervenes in the synthesis and metabolism of many compounds, like tyrosine, folic acid and tryptophan, hydroxylation of glycine. It facilitates the conversion of cholesterol into bile acids and hence lowers blood cholesterol levels and increases the absorption of iron in the gut by reducing ferric to ferrous state. Finally, it acts as antioxidant, protecting the body from various deleterious effects of free radicals, pollutants and toxins by reported literature [66]. However, being vitamin $\mathrm{C}$ sensitive to heat and oxygen, it is rapidly oxidized, so much so that its concentration in the Moringa oleifera dried leaves is lower than in the fresh leaves, dropping to 18.7 to $140 \mathrm{mg} / 100$ $\mathrm{g}$ of DW [67]. Therefore, this study aligned with the level of AA content reported by previous worker.

The normal level should be monitored in foods for consumption. According to RDA limits dietary allowance of AA in food to be $90 \mathrm{mg}$ for male and $75 \mathrm{mg}$ for female. The Food and Agricultural Organization of the United Nations (FAO) then their vitamin C intake would be between $210-280 \mathrm{mg} / 100 \mathrm{~g}$. The analyzed sample in this study contained relatively low to moderate amounts of total AA that were the acceptable range $(237.47 \pm 0.0310$, $239.96 \pm 0.0121) \mathrm{mg} / 100 \mathrm{~g}$ (Table 4.5). These results which indicate or suggest that, the consumer should use no more than these foods per day [24]. However, the analyzed Ms Leave sample in this study is safe for consumption with little or no effect on the body system since it contains optimum amount of AA; less than 75 or $90 \mathrm{mg}$ (FAW). Moreover, the finding of the study in Ms Leave was reported to contain $237.47 \pm 0.0310 \mathrm{mg}$ and $239.96 \pm 0.0121$ $\mathrm{mg}$ of AA/100g of dry weight for Konso and Arbaminch, respectively.

\subsection{Recovery analysis for HPLC method}

In order to evaluate the extraction efficiency of the standard method, spiked sample analysis was performed using standard solutions. The validity of the method was checked with the amount added and the amount recorded by the HPLC. First the sample concentration (without spiking) was detected using HPLC. The Standard stock solution of the AA used as a spiking solution. The amount of spike concentration was $10 \mathrm{mg} / \mathrm{L}$. The volume of spiking solution is calculated as:

$$
\begin{gathered}
\text { Volume of spike to add }=\frac{\text { choosen spike conc. } \times \text { Extraction volume }(\text { sample volume })}{\text { Concentration of stock(spiking)solution }} \\
\text { Volume of spike to add }=\frac{10 \mathrm{mg} / \mathrm{L} \times 50 \mathrm{ml}}{20 \mathrm{mg} / \mathrm{L}}=25 \mathrm{ml} \text { Spike to add }
\end{gathered}
$$

Added $25 \mathrm{ml}$ of $20 \mathrm{mg} / \mathrm{L}$ spiking solution to $5 \mathrm{ml}$ of sample solution. The volume of the spike was added to the $50 \mathrm{ml}$ sample. Then it was detected using HPLC and the concentration of spike plus sample was recorded. The $\%$ recovery was calculated using the formula as follows:

$$
\text { Recovery }(\%)=\frac{\text { Cs in the spiked samples }-\mathrm{Cs} \text { in the non }- \text { spiked samples } \times 100 \% \ldots \ldots \ldots . \text { eq } 4.2}{\text { spiked concentration }}
$$

Where, $\mathrm{C}_{\mathrm{s}}=$ concentration of total AA in each sample of interest. The result is indicated in Table 4.7.

Table 4.3 Recovery test for analysis of Ethiopian M.stenopetala leave sample from konso and Arbaminch

\begin{tabular}{|l|l|l|l|l|l|l|}
\hline S/N & Samples & Status & $\begin{array}{l}\text { AA in un- spiked } \\
\text { sample } \\
(\mathrm{mg} / \mathrm{L})\end{array}$ & $\begin{array}{l}\text { Spike } \\
\text { concentration } \\
(\mathrm{mg} / \mathrm{L})\end{array}$ & $\begin{array}{l}\text { AA in spiked } \\
\text { sample (mg/L) }\end{array}$ & Recovery (\%) \\
\hline 1 & $\begin{array}{l}\text { M.stenopetala } \\
\text { from konso }\end{array}$ & Fresh & $6.744 \pm 0.00778$ & 10 & $18.21 \pm 0.002121$ & $107.1 \pm 0.00771$ \\
\hline 2 & $\begin{array}{l}\text { M.stenopetala } \\
\text { fromArbaminch }\end{array}$ & Fresh & $7.889 \pm 0.005454$ & 10 & $18.79 \pm 0.00141$ & $109.01 \pm 0.0063$ \\
\hline
\end{tabular}

As Table 4.7 SHOWS, the results of percentage recoveries for the studied AA in Ms sample lied within the range (107-109) \%, which is in the acceptable range of $85-115 \%$ [68], this confirms that, the laboratory performance for each analyte is in control and the optimized extraction procedure was valid and/or accurate of determination of AA in M.stenopetala leave sample.

\subsection{Comparison of the two methods}

In the present study, comparison of the two methods indicated that the AA content that was analyzed by UV-Vis sphectophotometry method produced slightly comparable with the standard HPLC method for the M. stenopetala leave sample. The inconsistency of the results between the two methods might be due to the difference of the extraction procedure, analytical technique and effect of different experimental variables that we used for analysis. At the side of the modified UV-Vis sphectophotometry method could be affected by different experimental variables since it was new method. However, in terms of linearity, validate accuracy and reproducibility of the proposed method was alien with the standard HPLC method. In both methods, the amount of AA in cooked Ms Samples was lower than Fresh M.stenopetala samples.

\section{Conclusions}

In this study, a modified Spectrophotometric method was successfully applied for the determination of Ascorbic 
acid content in M.stenopetala leaves sample through catalytic titration with hexavalent chromium in presence of $\mathrm{Mn}(\mathrm{II})$ as a catalyst. The modified method was validated to against HPLC-VWD/DAD as a standard technique. In addition, discrepancies could also be due to differences in preparation of the samples, extraction technique, solvent use and analytical techniques.

As discussed in the previous section, AA is one of the main chemical compounds in Ms leave sample and has wide variety of health benefits and has harmful effect( if taken in excess)since it affects Ms leave quality, determination of the level of AA in a given green leave vegetable is very critical for consumer and producer /supplier . In this study the AA level of Ms Leave sample from Arbaminch, Konso and Dilla area were found in South Ethiopia, were successfully determined using modified UV-Vis spectrophotometer and HPLC method.

The Moringa stenopetala leave contained relatively moderate amount or acceptable range of AA (the range of $250-280 \mathrm{mg} / 100 \mathrm{~g}$ of AA dry weight according to FAW). Out of three variety of M.stenopetala leave sample which collected from different area of the country studied contained the highest concentration of AA was found in Arbaminch, as compare to both Konso and Dilla, respectively. But after cooking or boiling for ten minute of Ms Leave, the amount of AA become significantly reduced.Therefore, these conclude that, the studied Ms leave Samples are safe for human consumption especially after cooking. (at $\mathrm{p}<0.05$, there were a significance difference in the value obtained for AA in FMs and CMs). In summary, the results show that the M.stenopetala leave samples considered in this study contained moderate amount of AA (between $250-280 \mathrm{mg} / 100 \mathrm{~g}$ of AA dry weight) which is recommended according by FAW and also values found in the present study are in agreement with the values reported with standard of WHO .

\section{References}

[1]. Yalemtsehay M. The multi-purpose Moringa tree, Addis Abeba University, Vol.10, 2013, 67-75

[2]. khateeb W, Bahar E, Lahham J, Schroeder D and Hussien E. regeneration and asisment of genetic fidelity of endanger tree of M.stenopetala(forsk), fiori using inter simple sequence repeat(ISSR) physio mol bio plant, vol. 19, 2013, 157-164.

[3]. Iqbal S and Banger M. effect of season and production location on antioxidant activity of M. stenopetala leaves grown on Pakistan. J food compost Anal, vol. 12, 2006, 544-551.

[4]. Assefa A ,Emiru B ,Tewodros T and Kiros M H. Moringa stenopetala Tree Species Improved Sele Socioeconomic Benefits in Tigray, Northern Ethiopia, Sci. Technol. ArtsRes.vol. 4(2), 2015 ,68-78.

[5]. Gopalan C, Rama .BV and Balasubramanian SC. Nutritive value of Indian food, Indian; national institution of nutrition, Indian council of Medical research, 1989, 547-549.

[6]. Diriba B K, Edward JM Joy, Scott D Y, David W O, Louise A and Martin R B. Variation in the mineral element concentration of Moringa oleifera Lam. and M. stenopetala (Bak. f.) Cuf.: Role in human nutrition, PLOS ONE,12(4),2017,81-88

[7]. Afsharyepour S, Asghari G, Mohageheghzadeh A and Dehshahrire S. volatile constituent of seed kernel and M.stenopetala, Fiori Agrecolt. Cultivated chabahar (Iran) J Pharm Sci. vol 6, 2010, 141-150.

[8]. Danmalam HU , Abubakar Z and katsayal UA. Pharmacogenostic studies on the leaves of M.stenopetala, Niger .J Nat prod Med. vol 5, 2001, 4-9.

[9]. Marczenko Z. Separation and Spectrometric Determination of Elements, Ellis Horwood series in Analaytical chemistry, west Sussex, UK; Jhon Wiley and sons, vol 2 , 1986 140-145.

[10]. Sadek K. Chemotherapeutic efficacy an ethanolic M.stenopetala leaves extracts against chromium induced testicular toxicity in rate, Anderologia, vol 46, 2014, $1047-1054$.

[11]. Uchenna M N , Nwankwo V U ,Kayode P B. and Juliana U. Anti-nutrient, vitamin and other photochemical compositions of old and succulent moringa (Moringa oleifera Lam) leaves as influenced by poultry manure application, African Journal of Biotechnology, Vol 14, 2014, 2501-2509.

[12]. Ezeile C O, Aguzue C and Thomas S A. Effect of Brewing Time and Temperature on the release of Manganese and Oxalate from Lipton Tea and Azadirachta Indica (Neem), Phyllanthus Amarus and Moringa Oleifera blended Leaves, J. Appl. Sci. Environ. Manage, Vol.15 (1), 2011,175 - 177.

[13]. Shirley M Na. and Subila S. Study on the presence of oxalate ions in guava and sapota fruits, International Journal of Advanced Science and Researchindea, Issue 1, Vol.2, 2017, 15-17.

[14]. Nagendran B, Kalyana S and Samir S. "Phenolic compounds in plants and agri-industrial by-products: Antioxidant activity, occurrence, and potential uses," Food Chemistry, vol.99, 2006, 191-203.

[15]. Ghosh M C., Gelerinter E. and Gould E. S. Electron transfers 111 dis proportionation of carboxylatobound Cr (IV) Catalysis by Mn (II). Inorganic Chemistry., vol.31, 1992, 702-705.

[16]. Dereje B, Minaleshewa A and Mirtachew T A. Determination of some selected secondary metabolites and there in vitro antioxidant activity in commercially available Ethiopian tea (Camelliasinensis), SpringerPlus, vol 5, 2016, 1-9.

[17]. Gaithersburg M D. Association of Analytical Communities (AOAC). Official Methods of Analysis International,vol.24, 1984, 974-81. 
[18]. Teklit G. A., Chemical Compositions and Nutritional Value of Moringa Oleifera Available in the Market of Mekelle, Journal of Food and nutrition sciences,vol.3(5), 2016, 187-190

[19]. Xiang-Rong X. , Hua-Bin L., Xiao-Yan L.and Ji-Dong G., Reduction of hexavalent chromium by ascorbic acid in aqueous solutions, Chemosphere, vol. 57 ,2004, 609-61.

[20].Dehshahrire S, wink M, Afsharyepour S, Asghari.G and Mohageheghzadeh A. Antioxidant activity of methanolic leaf extract of M.peregrina (Forssk) Fiori, Res pham sci, vol. 7 (2), 2012, 111-118.

[21]. KeLiu Z S. and Shiqing Z. ,Reduction of hexavalent chromium using epigallocatechin gallate in aqueous solutions: kinetics and mechanism, Royal society of chemistry Advance, vol.6,2016,671-96.

[22]. Murphy E W., Criner, P.E. and Gray, B.C. Comparisons of methods for calculating retentions of nutrients in cooked foods. Journal of Agricultural and Food Chemistry.vol. 23, 1975, 1153-1157.

[23]. Pelin G E. and Cevdet N., Determination of Organic Acids in Olive Fruit by HPLC, Czech J. Food Sci, Vol. 28(3), 2010, 202-205.

[24].Hietavala T, Enni-MS Jeffrey R, ,Lynda A P, Risto P, Hannu S, Harri S and Harri M A. Dietary acid load and renal function have varying effects on blood acid-base status and exercise performance across age and gender, Applied Physiology, Nutrition and Metabolism, vol 42 (12), 2017,1330-1340.

[25]. Abacan S F., Hurtada W.A. and Devanadera M.A.R, Effects of cooking time, temperature, and salt concentration on the phenolic content and antioxidant activity of selected edible mushrooms, international Food Research Journal, vol.24(5), 2017 ,2028-2032.

[26]. Binesh Np .singhal R.S. and pandit A.B. , A study on degradation kinetic of Ascorbic acid in drumstick ( Moringa oleifera) leave during cooking, J sci Food agric,vol.85, 2005,1953-8.

[27].Vijayaraj. R.S. and Jyothirmaie, M. P. Analytical process of drugs by UV-Vis spectroscopy a review, International Journal of Pharmaceutical Research and Analysis, vol. 2, 2012, 72-78.

[28].Fuglie L. J, and Sreeja .K .Cultivation of Moringa. Http://moringafarms.com/161/cultivation of moringa, vol.12 (5), 2011,211-17.

[29].Uchenna M N., Nwankwo V U., Kayode P B and Juliana U. Anti-nutrient, vitamin and other phytochemicals compositions of old and succulent moringa (Moringa oleifera Lam) leaves as influenced by poultry manure application, African Journal of Biotechnology, vol. 14(32), 2015, 2501-2509.

[30].Gholamreza A., Abbasali p and Behnoshe B. Quantitative analysis of nutritional component in leaves and seed of the Persian moringa peregrine, pharmacognosy research,vol.7(3) , 2015, 242-248.

[31].Khondoker S A., Rajib B M. ,Hemayet H and Ismetara J. Vitamin C (L-ascorbic acid) Content in Different parts of Moringa oleifera Grown in Bangladesh, DOI 109734, ACSJ, 2016, 21119-21.

[32].Ramachandran C., Peter, K.V. and Gopalakrishnan, P.K. Drumstick (Moringa oleifera): A multipurpose Indian vegetable. Econ. Bot.,vol.34, 1980, 276-283.

[33]. Gnagnarella, P, Salvini, S. and Parpinel M. Food Composition Database for Epidemiological Studies in Italy. Available online: http://www.bda-ieo. vol.16 , 220-28,2015.

[34]. Chambial, S. Dwivedi, S Shukla, K K John, P J and Sharma, P. Vitamin C in disease prevention and cure: An overview. Indian J. Clin. Biochem.vol.28, 2013, 314-328.

[67]. Alessandro L ,Alberto S , Alberto B , Alberto S ,Junior A and Simona B. Cultivation, Genetic, Ethnopharmacology, Phytochemistry and Pharmacology of Moringa oleifera Leaves, nt. J. Mol. Sci.vol.16, 2015, 12791-12835.

[68]. Charde, M S ,Welankiwar, A S and Kumar, J. Method development by liquid chromatography with validation, International Journal of Pharmaceutical Chemistry. vol.4, 2014, 57-61. 